\title{
ANALYSIS OF THE WATER COLLECTION, TREATMENT AND DISTRIBUTION PROCESS IN BENJAMIN CONSTANT - AM CITY SANITATION COMPANY
}

\author{
Eleodoro Rodriguez Hermenegildo ${ }^{1}$, José Antônio Da Silva Souza ${ }^{2}$, Ricardo Silva Parente ${ }^{3}$, Italo Rodrigo \\ Soares Silva ${ }^{4}$, Jorge de Almeida Brito Júnior ${ }^{5}$, Paulo Francisco da Silva Ribeiro ${ }^{6}$
}

\author{
${ }^{1}$ Student, University Federal of Pará - UFPA, Manaus, Amazonas, Brazil. \\ ${ }^{2}$ Teacher, University Federal of Pará - UFPA, Manaus, Amazonas, Brazil. \\ ${ }^{3,4}$ Student, University Paulista - UNIP, Manaus, Amazonas, Brazil. \\ ${ }^{5,6}$ Research Department, Institute of Technology and Education Galileo of the Amazon (ITEGAM), \\ Manaus, Amazonas, Brazil.
}

Email: eleodoro.rodriguez@hotmail.com,jass@ufpa.br, ricardosilvaparente@gmail.com, italo.computation@gmail.com, jorge.brito@itegam.org.br

Received: August 13th 2019

Accepted: August 14 $4^{\text {th }}, 2019$

Published: September $30^{\text {th }}$, 2019

Copyright $(02016$ by authors and Institute of Technology Galileo of Amazon (ITEGAM).

This work is licensed under the Creative Commons Attribution International License (CC BY 4.0). https://creativecommons.org/lice nses/by/4.0/

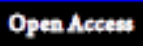

\section{ABSTRACT}

In recent decades there has been a widespread recognition that water supply systems for human consumption, in addition to complying with legal standards, must present levels of performance that merit the confidence of consumers in the quality that is provided to them The objective of this work aims to analyze the processes and phases of abstraction, treatment and distribution of water by the municipal sanitation company of Benjamin Constant -AM, in addition to evaluating the economic valuation of water, which is part of the privatization model of basic sanitation services, taking as object of analysis, the characteristics adopted by the responsible COSAMA concessionaire. The methodology consisted in the evaluation of the sanitary conditions, as well as compliance with the accepted legal standards for potability of water for human consumption, based on Portaria n ${ }^{\circ} 2914 / 2011$ of the Ministry of Health, which establishes potability for public supply. In addition to addressing also the calamity crisis in the year 2015 , found in the city. Seeking this, always understand about the importance of water in a global context, such as its economic valuation and public sanitation policies. The results indicated that the concessionaire COSAMA, in the role of supply water abstraction, treatment and distribution, have fulfilled their contracts with the public power in the municipality and performing their services, to meet the social demands, especially in areas with properly registered users showing periodically the analyzes of the treated water.

Keywords: Water-Treatment Plants-Amazon, Water-Purification, Water Supply - Economics.

\section{ANÁLISE DO PROCESSO DE CAPTAÇÃO, TRATAMENTO E DISTRIBUIÇÃO DE ÁGUA NA COMPANHIA DE SANEAMENTO DA CIDADE DE BENJAMIN CONSTANT - AM}

\section{RESUMO}

Nas últimas décadas tem-se assistido um reconhecimento generalizado de que os sistemas de abastecimento de água para consumo humano, além de satisfazer as normas legais, devem apresentar níveis de desempenho que mereçam a confiança dos consumidores na qualidade que lhes é fornecida. O objetivo deste trabalho visa a analisar os processos e fases de captação, tratamento e distribuição da água pela companhia de saneamento do município de Benjamin Constant - AM, além de avaliar sobre a valoração econômica da água, que se enquadra no modelo de privatização dos serviços de saneamento básico, tomando como objeto de análise, as características adotadas pela concessionária responsável COSAMA. A metodologia consistiu na avaliação das condições hidro sanitárias, além do atendimento aos padrões legais aceitos para potabilidade de água para consumo humano, com base na Portaria n 2914/2011 do Ministério da Saúde, que estabelece a potabilidade para o abastecimento do público. Além de abordar também sobre a crise de calamidade no ano de 2015, constatada na cidade. Buscando assim, compreender sempre sobre a importância da água em um contexto mundial, como a sua valoração econômica e as políticas públicas de saneamento. Os resultados indicaram que a concessionária COSAMA, no papel de fornecimento captação, tratamento e distribuição de água, têm cumprindo seus contratos junto ao poder público no município e realizando seus serviços, para atender as demandas sociais, principalmente para nas áreas com usuários devidamente cadastrados mostrando periodicamente as análises da água tratada.

Keywords: Água-Estações de tratamento-Amazonas, Água-purificação, Abastecimento de água - Aspectos econômicos. 


\section{INTRODUÇÃO}

Tem-se registrado um acelerado progresso no campo dos estudos ambientais, a partir das últimas décadas, do século passado, sendo descobertas valiosas para o desenvolvimento humano e algumas constatações trágicas do mau uso pelo ser humano a respeito dos recursos naturais, colocados ao alcance e atrelados a sua existência.

O monitoramento da qualidade da água destinada ao consumo humano da população rural torna-se, portanto, imprescindível, principalmente das águas que abastecem vilas e comunidades rurais, as quais possuem maior concentração de pessoas. Isso previne o aparecimento de várias doenças no homem, auxilia o diagnóstico das principais formas de contaminação e indica um conjunto de práticas de manejo dos recursos naturais que possibilitem o controle da poluição e um aumento da qualidade de vida dos usuários dessa água [1].

A água sem tratamento ou a precariedade do saneamento constituem a segunda maior causa mundial de morte infantil. As doenças provocadas pela água obrigam, todo ano, a 443 milhões de crianças ficarem um dia sem ir para a aula, o que equivale a um ano letivo inteiro para todas as crianças de sete anos na Etiópia. Além disso, as infecções parasitárias transmitidas pela água e pelo mau saneamento atrasam o potencial de aprendizagem de mais de 150 milhões de crianças [2].

No entanto, a disponibilidade e o abastecimento da água são fatores determinantes para a saúde, qualidade de vida e desenvolvimento socioeconômico da humanidade desde a antiguidade. Diversas pesquisas arqueológicas apontam projetos de captação e condução de água dos rios e lagos para as cidades, e principalmente, para a irrigação em áreas de cultivo a milhares de anos [3].

O crescimento desordenado de grandes centros urbanos tem causado pressão dobre os recursos hídricos locais, gerando a necessidade de se buscar novas fontes de abastecimento em locais cada vez mais distantes e com maiores investimentos. É importante destacar que antes da mudança de manancial devem ser concentrados esforços no sentido de adequar e ampliar as ETA implantadas, com ênfase para o máximo aproveitamento das unidades existentes [4].

Pesquisas sugerem que as respostas ecológicas e ambientais do meio aquático são imprevisíveis sobre os aspectos qualitativos e temporais, mesmo com a eliminação de todos os pontos de degradação existentes [5].

Sendo assim, a água é um recurso natural indispensável à vida e a toda atividade biológica e também um elemento fundamental para o equilíbrio natural e geodinâmico do planeta.

Água e energia estão sujeitas a pressões de mesma natureza: demográficas, econômicas, sociais e tecnológicas. Nesse contexto, promover a eficiência hidráulica e energética de sistemas de abastecimento de água (SAAs) torna-se um objetivo estratégico para o alcance da sustentabilidade de cidades e nações, uma vez que, na sua maioria, tais sistemas demandam grandes montantes de energia elétrica para bombeamento, ao mesmo tempo em que perdem significativa parcela da água captada durante o processo de disponibilização [6].

Para garantir a integridade químico-física e microbiológica da água, são realizados estudos com o intuito de conhecer as propriedades da mesma e verificar sua potabilidade [7]. Uma vez que é de responsabilidade do Órgão que administra o abastecimento de água no município, garantir o controle a distribuição do recurso hídrico às residências e demais estabelecimentos.
Apesar da complexidade do abastecimento de água na microrregião, devido às peculiaridades ambientais, urbanização desordenada, dificuldades financeiras e socioculturais, torna-se necessária uma abordagem transdisciplinar que possibilite a efetivação de políticas de uso e gestão concisas, capaz de propiciar equidade no acesso à água e, consequentemente melhorar as condições de vida de todos os cidadãos [8].

Por isso, caracteriza-se pelo recurso de que o homem necessita para satisfazer as suas necessidades de base. A água não é substituível. A água foi única e sempre será.

Portanto, este trabalho irá apresentar as etapas de captação, tratamento e distribuição da água, realizada pela estação de tratamento, visando abordar o município de Benjamin Constant - AM, sendo a concessionária COSAMA responsável sobre os serviços prestados no município.

Bem como citar sobre o ocorrido no ano de 2015, quando a cidade decretou calamidade pública, pela falta e necessidade de saneamento básico, devido às cheias que o Estado sofreu.

O presente artigo apresenta o processo de captação, tratamento e distribuição de água, no Município de Benjamin Constant- AM, distribuída pela concessionária COSAMA, por meio da Identificação das fases do funcionamento do sistema de captação de água, tratamento e distribuição dos equipamentos utilizados no processo, em conjunto com a analise dos resultados da pesquisa avaliando os serviços prestados de captação, tratamento e distribuição de água disponibilizados pela concessionária COSAMA para a população. Demonstrar os resultados da pesquisa aplicada na concessionária COSAMA, apresentando os benefícios alcançados após a aplicação do estudo de caso é um dos objetivos deste trabalho.

\section{REVISÃO DA LITERATURA}

\section{II.1 ÁGUA PLUVIAL}

Nosso planeta onde vivemos, encontra-se coberto por mais de dois terços de água e muitas vezes o apelidamos de planeta azul. O acesso à água não é uma questão de escolha. Todos os seres humanos dependem deste precioso líquido para viver. A água deverá, pois, ser encarada como um fator de união entre os homens e não como o móbil para disputas e atritos.

Apesar da elevada disponibilidade de água, a situação dos recursos hídricos no Brasil não é nada confortável. Mais de $70 \%$ da água que passa no território brasileiro está localizada na bacia do Rio Amazonas, onde vivem somente cerca de 5\% da população brasileira, sobrando apenas $30 \%$ para o restante do território brasileiro, onde vivem aproximadamente $95 \%$ da população [9].

A água constitui-se um dos recursos mais importantes para o progresso da sociedade contemporânea. Pois nenhuma sociedade pode viver e se evoluir sem o abastecimento de água, que permite que seus habitantes se reproduzam de modo saudável e confortável e, consequentemente, contribuindo também para o desenvolvimento da economia.

No Brasil, até aproximadamente 20 anos atrás existiam poucas experiências de aproveitamento de água pluvial. Hoje, já existe no país a Associação Brasileira de Manejo e Captação de Água de Chuva, que é responsável por divulgar estudos e pesquisas, reunir equipamentos, instrumentos e serviços sobre o assunto [10].

A escassez e a má utilização dos recursos hídricos conduziram a que a ONU considerasse a água o principal tema do Século XXI, e declarasse o ano de 2003 o Ano Internacional da Água Doce. 
Sendo assim, o abastecimento público, é o processo mais adequado de suprimento de água para toda população, principalmente em áreas urbanas e suburbanas, pois a concessionária deve preencher todos os requisitos de potabilidade da água. No Brasil, a Portaria do Ministério da Saúde no 518/2004, descreve os procedimentos e responsabilidades ao controle e vigilância da qualidade da água, ideal para o consumo humano e seu padrão de potabilidade.

Porem a Portaria de Consolidação de Leis em Saúde $\mathrm{N}^{\circ}$ 5 de 28/09/2017 na página 18, cap. 5, artigo 128, seção 1 e 1l, aprova as normas e padrões sobre fluoretação da água dos sistemas públicos de abastecimento, destinada ao consumo humano.

\section{II.2 SISTEMAS DE ABASTECIMENTO}

Como definição o sistema de abastecimento público de água constitui-se no conjunto de obras, instalações e serviços, destinados a produzir e distribuir água a uma comunidade, em quantidade e qualidade compatíveis com as necessidades da população, para fins de consumo doméstico, serviços públicos, consumo industrial e outros usos [11].

Para [12], os sistemas de abastecimento de água são projetados para proporcionar o fornecimento contínuo de água com qualidade satisfatória e pressão suficiente a todos os consumidores.

De acordo com [13], o sistema de abastecimento de água pode ser variável de acordo com a concepção da cidade, em função do seu porte, topografia e a posição que se encontra em relação aos mananciais, rios, etc.

Segundo informações da Agência Reguladora de Águas, Energia e Saneamento Básico do Distrito Federal [14], um Sistema de Abastecimento de Água (SAA) é composto por diversas unidades:

a) Mananciais:

Segundo [15] são locais que fornecem o abastecimento de água para a população, estes locais podem ser constituídos de uma fonte subterrânea ou superficial, sendo que estas fontes devem ser suficientes para atender a demanda de projeto imposta pelo município.

Essa fonte deve fornecer vazão suficiente para atender a demanda de água em um período de projeto, e a qualidade dessa água deve ser adequada com as normas sanitárias, previsto que são as concessionárias de abastecimento de água que devem regularizar e fornecer água com qualidade.

b) Captação:

É o conjunto de equipamentos e instalações utilizadas para a retirada de água do manancial, fontes da água captada dos rios, barragens, lagos e poços subterrâneos;

De acordo com [16] a captação da água (bruta) nos mananciais é uma atividade prescrita e regulamentada por lei. Essa atividade é descrita e depende da outorga de direito de uso da água, concedida pelos órgãos públicos responsáveis, em âmbito estadual ou federal. Em se tratando do direito de uso da água, ou seja, dos recursos hídricos de domínio da União, é regulamentada pela Agência Nacional de Águas (ANA), como está previsto pela Lei ${ }^{\circ}$ 9.984, de 17 de julho de 2000.

Segundo [15], é necessário uma série de projetos e obras para conseguir retirar água de um local. Para que se tenha captação de água dos mananciais de superfície, as obras devem ser de proporções de acordo com o porte do manancial, considerando a topografia e geologia do local, assim como a qualidade e a variação do nível de água. As obras que compõem o sistema de captação devem fornecer condições de fácil entrada da água e assegurar a melhor qualidade possível.
Após o processo de captação, a água é conduzida através de adutoras até a estação de tratamento. A adução deve ser feita por tubulações sob pressão ou por canais constituídos pela condução de escoamento livre da água, considerando a topografia do local. E é nas estações de tratamento, que é realizado todos os procedimentos para tornar a água potável para o consumo humano. [16].

A captação da água de superfície pode ser feita sobre cinco tipos:

Captação por meio de reservatórios de regularização de vazão com a prioridade de abastecimento público de água;

Captação com barragem de regularização de nível de água;

Captações não convencionais;

Captação em reservatórios ou lagos de usos múltiplos;

Captação direta ou a fio de água.

\section{II.3 TRATAMENTO}

Segundo a NBR 12216, uma ETA é composta de um conjunto de unidades que tem como objetivo, produzir uma água com padrões adequados de potabilidade.

O sistema de tratamento da água tem a finalidade de redução de impurezas presentes na mesma, tornando-a potável para o consumo. Sendo que o tratamento da água é realizado conforme a qualidade da água bruta retirada do manancial, podendo ser um tratamento com maior, ou menor complexidade.

Para [17], um sistema de tratamento convencional, ocorre segundo as etapas de:

a) Pré cloração: adição de agente oxidante (cloro) na água bruta, para combater algas e reduzir matéria orgânica;

b) Coagulação: Adição de coagulante, visando desestabilizar impurezas presentes na água e facilitar o aumento do tamanho das mesmas na etapa de floculação;

c) Floculação: Agitação da água realizada após a coagulação, com o objetivo de promover o contato entre as impurezas e, assim, aumentar o tamanho das mesmas moléculas da água por tanques, no fundo dos quais as impurezas;

d) Decantação: Passagem da água por tanques, no fundo dos quais as impurezas ficam depositadas;

e) Filtração: Remoção de material particulado e compostos orgânicos e inorgânicos indesejáveis, presentes na água. Os filtros geralmente são compostos por areia e carvão ativado;

f) Desinfecção e fluoretação: Processo destinado a inativar microrganismos patogênicos presentes na água, geralmente através da adição de cloro para manter a qualidade da água na distribuição e adição de compostos contendo o íon fluoreto, com a finalidade de combater a cárie infantil.

As águas de superfície são as que mais necessitam de tratamento, porque se apresentam com qualidades físicas e bacteriológicas impróprias, com exceção das águas de nascentes que com uma simples proteção das cabeceiras e cloração, podem ser muitas vezes consumidas sem perigo [11].

Embora seja comum se dizer que do ponto de vista técnico pode-se potabilizar qualquer tipo de água, os riscos sanitários e os custos envolvidos no tratamento de águas contaminadas podem ser muito elevados, exigindo o emprego de técnicas cada vez mais custosas e sofisticadas, motivo pelo qual devem ser priorizadas ações de proteção dos mananciais [10].

A Figura 1 mostra o fluxograma de Estação de tratamento de água completo, mostrando as etapas e os produtos químicos adicionados no processo. 


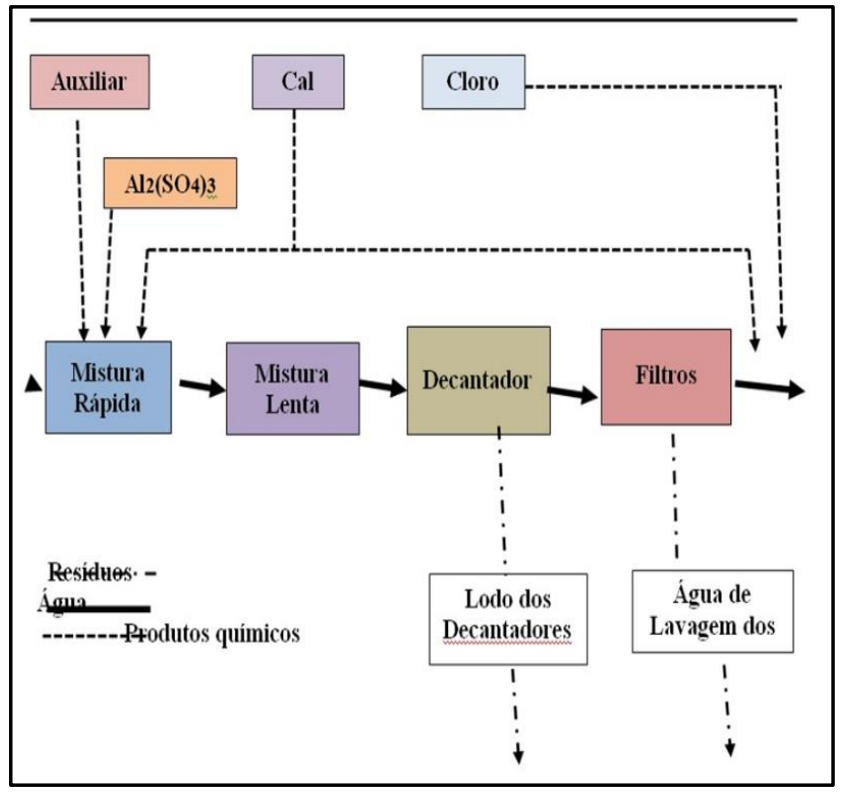

Figura 1 - Fluxograma de uma ETA convencional. Fonte: [17].

\section{II.4 SANEAMENTO BÁSICO}

A busca inconstante por respostas sobre as questões que envolvem o acesso e a disponibilidade da distribuição da água tem implicado sobre a forma de compreender e valorizar este recurso tão importante para a vida.

O juízo de valores está interligado com a educação no desenvolvimento sobre a consciência de conscientização ambiental, sobre os impactos que a humanidade causa ao meio ambiente, buscando assim, alternativas para equilibrar o uso deste recurso tão precioso, que é a água. A modificação dos costumes, sobre a racionalização de desperdícios e os usos indevidos da água, são exemplos para uma base de valorização. Sendo que esta ideia reflete diretamente na economia e na qualidade deste bem.

Outra forma de valorização está ligada a bases econômicas, como o controle do consumo da água, por meio das tarifas (preços). Assim, a água é considerada como um recurso econômico e defendida principalmente pelos métodos neoliberais.

De acordo com [18], a "economia neoclássica despreza, em seu formalismo, elementos relevantes da economia social (...)", sendo responsável pela determinação dos custos e sobre a influência dos comportamentos de mercado.

A valorização da economia de água é a política de saneamento básico que mais tem sido enfatizada, sendo assim, as medidas que relacionam a cobrança pela água, têm a transferência dos serviços de gestão as empresas privadas, as quais tem recebido maior atenção.

Contudo, a valorização da economia da água, não está associada somente a viabilidade dos investimentos, mas também a garantia sobre a qualidade e quantidade de água e a sua ampliação ao acesso para toda a população e ampliação do capital privado.

Em relação ao interesse privado na obtenção da água, os grupos transnacionais têm expandido o território, quanto à atuação da prestação dos serviços de infraestrutura e se dedicado as atividades relacionadas à água.

\section{MATERIAIS E MÉTODOS}

Os materiais e métodos deste estudo de caso analisado, trata-se sobre a captação, tratamento e distribuição da água, pela concessionária COSAMA, no município de Benjamin Constant do Estado do Amazonas.
O município se estende por $8.695,392 \mathrm{Km}^{2}$ e contava com 41.329 habitantes no último censo.

Os municípios vizinhos de Tabatinga e Atalaia do Norte, Benjamin Constant, se situam a $18 \mathrm{~km}$ a Sul-Oeste de Tabatinga sendo a maior cidade nos arredores.

O município de Benjamin Constant (Figura 2) situa-se a 83 metros de altitude, de Benjamin Constant tem as seguintes coordenadas geográficas: Latitude: $4^{\circ} 23^{\prime} 0^{\prime \prime}$ Sul, Longitude: $70^{\circ} 1^{\prime}$ 53" Oeste.

A presente pesquisa foi realizada na cidade de Benjamin Constant, município do interior do estado do Amazonas, localizada na microrregião ao alto Solimões, na mesma região do Sudoeste Amazonense, distante de Manaus $1.118 \mathrm{~km}$ em linha reta, sendo que a distância via transporte fluvial é de $1.638 \mathrm{~km}$, subindo o rio Solimões e o rio Javari. Benjamin Constant limita-se com os municípios de Tabatinga, São Paulo de Olivença, Ipixuna, Eirunepé, Jutaí.

Segundo dados do IBGE, a cidade apresenta $12,3 \%$ de domicílios com esgotamento sanitário adequado, sendo cerca de $12,8 \%$ de domicílios na zona urbanos em vias públicas com arborização e 6,6\% dos domicílios urbanos em vias públicas com urbanização adequada.

O abastecimento público de água compõe um dos serviços do tema saneamento básico. É o conjunto de medidas que visa preservar ou modificar as condições do meio ambiente com a finalidade de prevenir doenças e promover a saúde, melhorar a qualidade de vida da população e à produtividade do indivíduo. A Constituição Federal de 1988 afirma no inciso IX do art. 23 que é competência comum dos três níveis de governo promover melhorias das condições de saneamento básico à população. $\mathrm{O}$ mesmo diploma legal, no inciso VI, do art. 200, estabelece como competência do SUS, dentre outras atribuições, a fiscalização e inspeção de águas para o consumo humano [10].

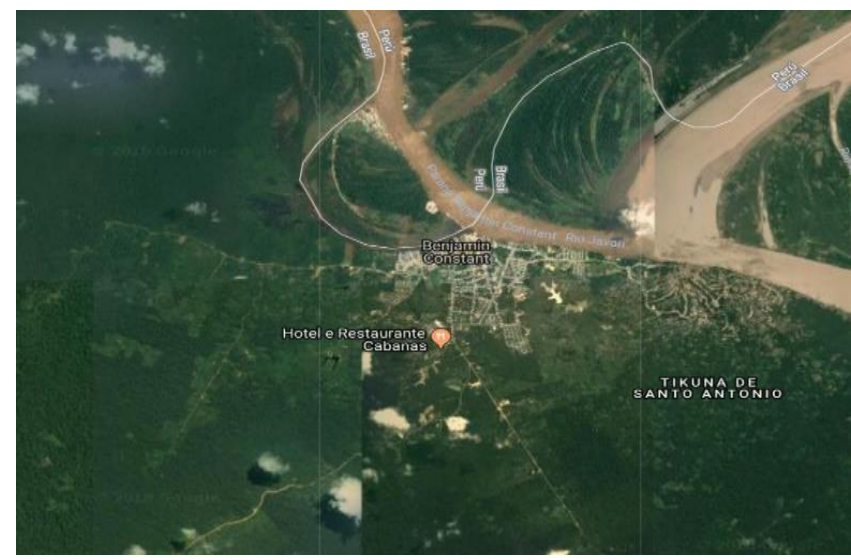

Figura 2 - A localização do município de Benjamin Constant -AM no mapa.

Fonte: [10].

A concessionária responsável pelo tratamento e abastecimento de água no município é a Companhia de Saneamento do Amazonas [10].

No Amazonas foi criada em 1969 a Companhia de Saneamento do Amazonas (Lei Estadual no 892, 13/11/1969), para a execução, operação, manutenção e exploração dos sistemas de abastecimento de água e esgotos sanitários da cidade de Manaus e das sedes municipais [10].

Acerca das concessões a COSAMA, informou na Carta $\mathrm{N}^{\circ}$ $369 / 2015$ - DP que as mesmas não estão totalmente oficializadas. Em Benjamim Constant, o convênio de outorga de concessão dos serviços, firmado em 1974 por um prazo de 30 anos, expirou em 2004 e está a 11 anos vencido [10]. 


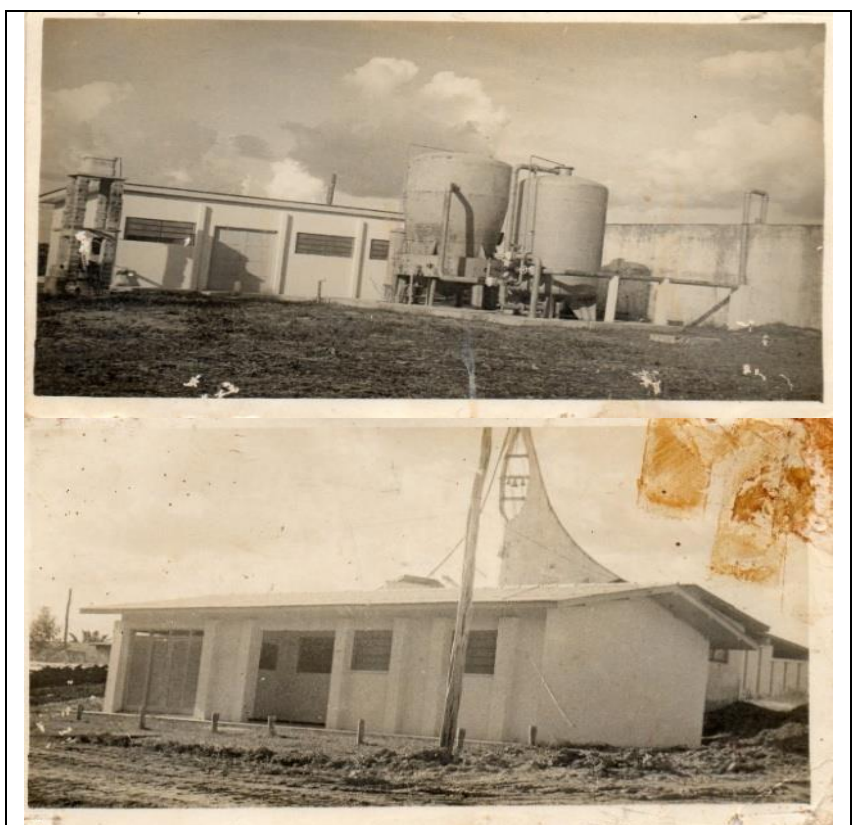

Figura 3 - Antigo reservatório e o antigo prédio da COSAMA no município.

Fonte: [10].

A Figura 3 mostra duas fotografias, uma da primeira Estação de Tratamento de Água, que inicialmente chamava-se: Sistema de Abastecimento de Água e Esgoto (SAAE). A segunda fotografia mostra o local do primeiro escritório e que ainda funciona no mesmo local só com nova imagem.

As atividades da empresa compreendem ainda na realização de estudos, projetos e execuções de obras, para novas instalações e ampliação das redes. Também é dever da companhia, fixar tarifas e taxas dos seus serviços para a população arrecadá-los e ajustá-los, periodicamente, frente à amortização dos investimentos e pagamento dos custos de operação e manutenção de todo sistema, além de permitir a acumulação de reservas financeiras na expansão de suas atividades.

A concessionária de abastecimento COSAMA está presente em 12 dos 62 municípios do Estado do Amazonas.

Possui como missão a prestação de serviço de forma adequada, compreendendo no sistema de saneamento básico, no equilíbrio econômico financeiro, universalizando o atendimento e contribuindo para a melhoria na qualidade de vida e saúde da população.

A visão da empresa está proposta em ser um modelo de gestão em saneamento básico para a região, sendo autossustentável, integrada e comprometida com a população, com o meio ambiente, prestando atendimento de qualidade e tendo um retorno da população, como forma de reconhecimento, dos fornecedores, colaboradores da empresa, acionistas e de forma geral o município.

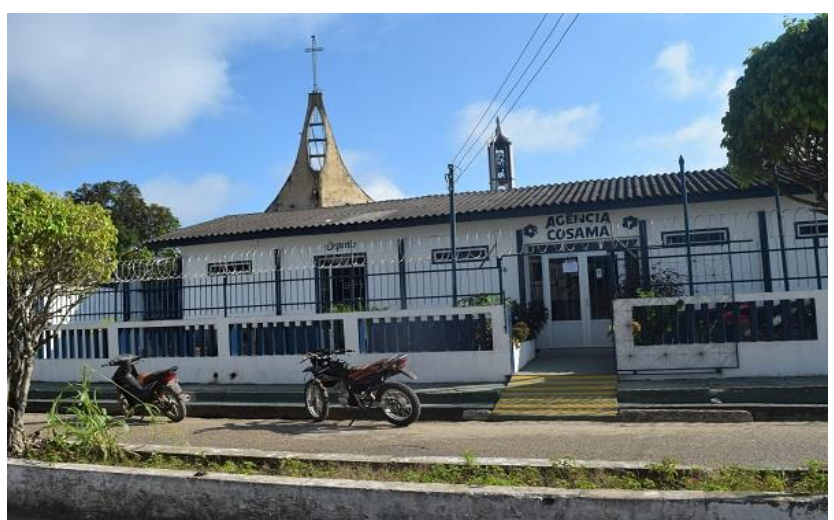

Figura 4 - Novo escritório atual da COSAMA 2018. Fonte: Autores, (2019).

A Figura 4 mostra a fotografia do escritório atual da concessionária COSAMA, o endereço é o mesmo desde quando iniciou as atividades em novembro de 1969. Passou por diferentes reformas, a imagem mostra a reforma de 2015.

AMAZONAS

\begin{tabular}{|c|c|c|c|c|c|c|c|c|c|c|c|c|}
\hline \multicolumn{11}{|c|}{ RESUMO dOS RESULTADOS DAS ANÁLISES DA QUALIDADE DA AGUA DISTRIBUIDA PELOS SISTEMAS OPERADOS PELA COSAMA } & \multicolumn{2}{|l|}{ MES: } \\
\hline MUNICIPIOS $>0000000000000$ & ALVARESES & AUTAZES & BENUWN & CARAUAO & C. VARZEA & COONES & EIRUNEPE & ITAMARATI & JRUA & TMANOUI: & SP.QUMENGA & TABATINGA \\
\hline COUFORMES TOTASS & & & VALORMA & XIMO PER & MiriDo uF & FCl100mi: & Austincias & m 95\% das & amostras & analisadas & & \\
\hline No de amostras realizadas & 30 & 43 & 42 & 60 & 20 & 48 & 55 & 32 & 24 & 36 & 81 & 56 \\
\hline$N^{\circ}$ de amostras andmalas & 0 & 0 & 0 & 0 & 0 & 0 & 0 & 0 & 0 & 0 & 0 & 0 \\
\hline 5 de atendimento & 98 & 100 & 94 & 95 & 90 & 100 & 100 & 100 & 95 & 100 & 100 & 100 \\
\hline$N^{\circ}$ amostras conformes & 30 & 43 & 42 & $\infty$ & 20 & 48 & 55 & 32 & 24 & 36 & 81 & 56 \\
\hline COLIFORMES TERMOTOLERANTES & & & & VALS & ORMAOIMC & OPERMITII & DOUFCII) & Dom $\mathrm{ml}:$ : Aus & Incia & & & \\
\hline$N^{0}$ de amostras realizadas & 30 & 43 & 42 & 60 & 20 & 48 & 55 & 32 & 24 & 36 & 81 & 56 \\
\hline$N^{\circ}$ de amostras andmalas & 0 & 0 & 0 & 0 & 0 & 0 & 0 & 0 & 0 & 0 & 0 & 0 \\
\hline$N^{\circ}$ amostras conformes & 30 & 43 & 42 & 60 & 20 & 48 & 55 & 32 & 24 & 36 & 81 & 56 \\
\hline COUFORMES HETEROTROFICAS & & & & & LORMAXI & MOPERM & IIDOC UFC & $200 \mathrm{ml}=50$ & & & & \\
\hline $\mathbb{N}^{\circ}$ de amostras realizadas & 30 & 12 & 34 & 60 & 20 & 48 & 23 & 7 & 12 & 24 & 65 & 24 \\
\hline$N^{\circ}$ de amostras andmalas & 0 & 0 & 0 & 0 & 0 & 0 & 0 & 0 & 0 & 0 & 0 & 0 \\
\hline$N^{6}$ amostras conformes & 30 & 12 & 34 & 60 & 20 & 48 & 23 & 7 & 12 & 24 & 65 & 24 \\
\hline CLORO LIVRE & & & & & IALORMA & XIMO PER & Mirioo $(\mathrm{ms}$ & $2]=0,2 / 5,0$ & & & & \\
\hline Mbdia de resultados (mg/L) & 1,40 & 1.90 & 1,40 & 1.60 & 2,40 & 2.17 & 0.84 & 1,30 & 2,18 & 1,50 & 2,00 & 1,40 \\
\hline$N^{\circ}$ de amostras realizadas & 120 & 334 & 350 & 60 & 337 & 57 & 95 & 120 & 120 & 126 & 498 & 381 \\
\hline$N^{-}$de amostras andomalas & 0 & 0 & 0 & 0 & 0 & 0 & 0 & 0 & 0 & 0 & 0 & 0 \\
\hline$N^{\circ}$ amostras conformes & 120 & 334 & 350 & 60 & 337 & 57 & 95 & 120 & 120 & 126 & 498 & 381 \\
\hline TURBIDEZ & & & & & VALORM & ASXIMOPE & RMITIDO & NTU) 5.0 & & & & \\
\hline Mbia de resultados (NTU) & 130 & 2,40 & 7,30 & 0,00 & 16.70 & 1.84 & 1,40 & 1,70 & 322 & 1.60 & 3.46 & 1.00 \\
\hline$N^{\circ}$ de amostras realizadas & 120 & 384 & 350 & 60 & 320 & 57 & 95 & 120 & 120 & 126 & 270 & 331 \\
\hline$N^{\circ}$ de amostras andmalas & 0 & 0 & 270 & 0 & 320 & 0 & 0 & 0 & 0 & 0 & 0 & 0 \\
\hline$N^{\circ}$ amostras conformes & 120 & 384 & 80 & 60 & 0 & 57 & 95 & 120 & 120 & 126 & 270 & 331 \\
\hline COR APARENTE & & & & & VALORN & WDOMOPE & ERMITIDO & $u(C)=15,0$ & & & & \\
\hline Media de resultados (UC) & 0.00 & 7.70 & 10.00 & 0.00 & 126.00 & 2.66 & 3.00 & 5.00 & 17.00 & 5.00 & 15,62 & 0.00 \\
\hline$N^{\circ}$ de amostras realizadas & 120 & 394 & 350 & 60 & 320 & 57 & 95 & 120 & 120 & 90 & 493 & 381 \\
\hline$N^{\circ}$ de amostras andomalas & 0 & 0 & 0 & 0 & 320 & 0 & 0 & 0 & 48 & 0 & 17 & 0 \\
\hline$N^{f}$ amostras conformes & 120 & 334 & 350 & 60 & 0 & 57 & 95 & 120 & 72 & 90 & 451 & 381 \\
\hline $\mathrm{PH}$ & & & & $\overline{V A L O R R}$ & ECOMENDA & ADOPELA & PORTARIA & 29142012 & 6.009 .5 & & & \\
\hline Media de resultados & 5.80 & 5.80 & 6.60 & 5.50 & 5.10 & 5.80 & 6.15 & 6.30 & 7,44 & 6.00 & 7,11 & 6.80 \\
\hline$N^{\circ}$ de amostras realizadas & 120 & 384 & 350 & 60 & 320 & 57 & 95 & 120 & 120 & 90 & 498 & 381 \\
\hline
\end{tabular}

Figura 5 - Resultado da análise da água em diferentes municípios julho de 2018.

Fonte: [10]. 
$\mathrm{Na}$ Figura 5 apresenta os resultados década análise realizada na qualidade da água pelo sistema operados da COSAMA de diferentes municípios em julho de 2018, em destaque em amarelo o município de Benjamin - AM.

\section{III.1 ESTADO DE CALAMIDADE PÚBLICA EM BENJAMIN C.- AM 2015}

Defesa Civil Nacional reconhece estado de calamidade pública em 2015 no município de Benjamin Constant (AM):

A Prefeitura de Benjamin Constant aguardou por homologação do Governo do Estado do decreto de Estado de Calamidade Pública no município devido a face da cheia que atingiu cerca de um terço da área urbana e 49 comunidades rurais.

Em 14 de Maio de 2015, o decreto declarou Estado de Calamidade Pública pela prefeita atuante na época. O Rio Solimões subiu em um nível de 13,77 metros, caracterizando a segunda maior enchente registrada nos últimos 16 anos. Faltou apenas cinco centímetros para bater a marca de maior cheia já registrada no ano de 1999, quando o nível das águas alcançou 13,82 metros.

O decreto de Estado de Calamidade Pública tem por base, reconhecer os agravamentos causados, como: os danos humanos, materiais, ambientais e prejuízos econômicos públicos e privados.

A inundação no município atingiu 2.000 famílias totalizando 12.185 pessoas. E o avanço das águas atingiu 33 instalações públicas dos quais 16 escolas (duas na área urbana e 14 nas comunidades rurais), três Unidades Básicas de Saúde, Mercado Municipal, Feira do Produtor, Porto Fluvial, 52 estabelecimentos comerciais dentre outras instalações.

O Estado de Calamidade decretado, por processo da defesa civil nacional, reconheceu como a emenda:

a) Situação de emergência, causada por situação anormal, devido ao desastre, com danos e prejuízos que implicam no comprometimento parcial da capacidade de resposta do poder público;

b) $\mathrm{O}$ reconhecimento da situação de emergência do município, ou do estado de calamidade pública, por meio de portaria da Defesa Civil Nacional, permite ao estado, Distrito Federal ou município, solicitou recursos da União para ações de socorro, assistência às vítimas, restabelecimento de serviços essenciais e reconstrução do município;

c) Para solicitar tais recursos, o município teve de manter um plano detalhado de respostas indicando qual é a necessidade para o repasse. É importante que o município tenha aderido ao cartão de pagamento de defesa civil, como forma exclusiva para os repasses de verbas, e que poderia ser acompanhado pelo Portal da Transparência.

\section{CONCLUSÕES}

Com a pesquisa foi identificado que a concessionária COSAMA, no papel de fornecimento captação, tratamento e distribuição de água, têm cumprindo seus contratos junto ao poder público no município e realizando seus serviços, para atender as demandas sociais, principalmente para nas áreas com usuários devidamente cadastrados. Sendo que a diminuição do percentual de desperdício de água está relacionada diretamente com o crescimento da populacional, onde são implantadas novas instalações de malhas de dutos, com materiais de qualidade e durabilidade, diminuindo a perda de recurso hídrico. Mas o problema devido às redes e malhas de dutos antigos, que não são substituídos, e do avanço urbano desordenado, crescimento das comunidades, que além de aumentarem o desperdício de recursos hídricos, resulta em problemas de abastecimento, decorrente das demandas não programadas. A COSAMA pode ser considerada socialmente responsável, já que oferece a seus usuários uma água de qualidade. Diante disso, e de todo exposto no trabalho, com os questionários realizados e os dos fatores e etapas apresentadas do plano de tratamento, conclui-se que as políticas públicas de gestão dos recursos hídricos precisam ser eficazes, bem como a fiscalização dos órgãos competentes responsáveis e também da sociedade civil, visando à preservação e o uso consciente desse bem que é essencial para desenvolvimento humano e da nação, ou seja, a água que a cada dia está se tornando escasso em decorrência as mudanças globais que estão acontecendo rapidamente.

\section{AGRADECIMENTOS}

Agradecimento especial ao Instituto de Tecnologia e Educação Galileo da Amazônia - ITEGAM pelo suporte técnico, científico e colaboração dos membros do instituto.

\section{REFERENCIAS}

[1] Gonçalves, C. S. Qualidade de águas superficiais na micro bacia hidrográfica do arroio Lino Nova Boêmia - Agudo - RS. 2003. $90 f$. Dissertação (Mestrado em Agronomia) - Universidade Federal de Santa Maria, Santa Maria, 2003.

[2] Programa das Nações Unidas para O Desenvolvimento (PNUD). Relatório do Desenvolvimento Humano 2006. A água para lá da escassez: poder, pobreza e a crise mundial da água. New York, 10017, USA. 1101p.

[3] Martins M.; Riveiro, M. do C. Gestão e uso da água em Bracara augusta. Uma abordagem preliminar. Martins eat al. (Org.). Caminho da água: Paisagem e usos na longa duração, p. 9-49, 2012.

[4] Agência Nacional de Águas (ANA). Disponível em: http://www2.ana.gov.br/Paginas/default.aspx. Acesso em: 28/07/18.

[5] Reynolds, C., Dokulil, M., Padisak, J. (2000). Understanding the assembly of phytoplankton in relation to the trophic spectrum: Where the we now? Hidrobiologia n.424, p. 147 - 152. 2000.

[6] Ricardo, Mateus Nogueira Vilanova. Desenvolvimento e avaliação de indicadores de eficiência hidráulica e energética para sistemas de abastecimento de água como ferramenta de suporte à tomada de decisões - SP, 31p. Dissertação de Doutorado em Engenharia Mecânica, Faculdade de Engenharia de Guaratinguetá da Universidade Estadual Paulista, Guaratinguetá, 2012.

[7] Vasconcelos. Ana Sofia Barbosa de. Estudo da qualidade da água do Rio Ave: relevância da relação entre indicadores microbiológicos, macro invertebrados e parâmetros físicoquímicos. 2015. 205 f. Tese (Mestrado em Biologia e Gestão da Qualidade da Água). Faculdade de Ciências, Universidade do Porto, Porto, 2015.

[8] Giatti, Leandro Luís. Reflexões sobre Água de Abastecimento e Saúde Pública: um estudo de caso na Amazônia Brasileira. Saúde e Sociedade, v. 16, n. 1, p. 134-144, 2007.

[9] Castro, C.N. Gestão das águas: experiência internacional e brasileira. IPEA. Brasília, 2012. ISSN 14415-4765. Disponível em hhttt://repositório.ipea.gov.br/bitstream/110588/1132/1/DT_1744. pdf. Acesso em 11-08-2018. 
[10] Hermenegildo, E. R. Análise do processo de captação, tratamento e distribuição de água na companhia de saneamento da cidade de Benjamin Constant - AM, Dissertação de Mestrado, Universidade Federal do Pará - UFPA, BELÉM-PA, 2018.

[11] Funasa - Fundação Nacional de Saúde. 4 edições - Brasília: Fundação Nacional de Saúde, 2006 núcleo de editoração e mídias de rede / Ascom/Presi/Funasa/MS.

[12] Santos, L. P. S.; Soares, A. K.; Silva, S. S. Eficiência hidroenergética em sistemas de distribuição de água: uma discussão teórica, p. 383-392 . In: Anais do XIV Encontro Nacional de Estudantes de Engenharia Ambiental. Blucher Engineering Proceedings v.3 n.2. São Paulo: Blucher, 2016. ISSN 2357-7592, DOI 10.5151/engpro-eneeamb2016-rh-0154842.

[13] Tsutiya, Milton Tomoyuki. Gerenciamento de perdas de água e energia elétrica em sistemas de abastecimento: nível 2 / Secretaria Nacional de Saneamento Ambiental (org). - Salvador: ReCESA, 2008.

[14] ADASA Agência Reguladora de Águas, Energia e Saneamento Básico do Distrito Federal. Disponível em: Acesso em 12 de novembro de 2018.

[15] Girol, Guilherme Violato. Análise de perdas reais em um setor do sistema de abastecimento de água no município de capinzal SC: formação. 2008. 62 f. Monografia (formação Engenharia Sanitária e Ambiental) - Universidade Federal de Santa Catarina. Curso de Graduação em Engenharia Sanitária e Ambiental. Capinzal, 2008.

[16] Tarso, Saulo; Pimentel, Heber. Macromedição. 3 ed. Paraíba,197 p., 2009.

[17] Oliveira, Cristiane Fernandes de. Água e Saneamento básico: A atuação do grupo Suez em Limeira e Manaus. São Paulo, Faculdade de Filosofia, Letras e Ciências Humanas, Universidade de São Paulo, 2007. 233 p. (Tese de Doutoramento em Ciências Geografia Humana).

[18] Martins, R. C. E Valencio, N. F. L. da S. A concretude da moderna crise socioambiental. In: Martins, R. C. e Valencio, N. F. L. da S. (Orgs.) Uso e Gestão dos Recursos Hídricos no Brasi: desafios teóricos e político-institucionais. São Carlos: RiMa, 2003. p.21-34. 